\section{REDIMAT}

Journal of Research in Mathematics Education
Hipatia Press

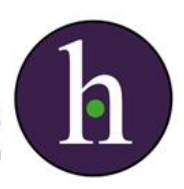

Instructions for authors, subscriptions and further details:

http://redimat.hipatiapress.com

\title{
The Direction and Autonomy of Interdisciplinary Study and Research Paths in Teacher Education
}

Klaus Rasmussen ${ }^{1}$

1) University of Copenhagen \& Metropolitan University College

Date of publication: June $24^{\text {th }}, 2016$

Edition period: June 2016-October 2016

To cite this article: Rasmussen, K. (2016). The direction and autonomy of interdisciplinary study and research paths in teacher education. REDIMAT, 5(2), 158-179. doi: 10.4471/redimat.2016.1753

To link this article: http://dx.doi.org/10.4471/redimat.2016.1753

PLEASE SCROLL DOWN FOR ARTICLE

The terms and conditions of use are related to the Open Journal System and to Creative Commons Attribution License (CC-BY). 


\section{The Direction and Autonomy of Interdisciplinary Study and Research Paths in Teacher Education}

Klaus Rasmussen

University of Copenhagen \&

Metropolitan University College

(Received: 02 October 2015; Accepted: 13 June 2016; Published: 24 June 2016)

\section{Abstract}

This paper presents a case study of didactic infrastructures to direct Study and Research Paths (SRP) in teacher education within the context of interdisciplinary inquiry. The disciplines of school mathematics and school biology, and their didactics, are made to interconnect through the investigation of a generating question concerning the illness diabetes. The resulting interdisciplinary knowledge as evidenced through students written diaries is analysed using the Anthropologic Theory of the Didactic and shows the challenge of combining two disciplines and their didactics at the same time. Two particular forms of didactic infrastructure to guide the self-sustained process of SRP are proposed and scrutinized: Selective picking and Side questions. Selective picking is shown to be a promising, yet indirect, infrastructure to steer the SRP without taking away the desired autonomy of the students. Side questions, initially proposed by Ives Chevallard, are considered in light of the case, and a number of suggestions for their characteristics and use are put forward.

Keywords: Interdisciplinary, self-sustained study and research processes, Anthropological theory of the didactic, teacher education, study and research path 


\section{La Dirección y la Autonomía en los Recorridos de Estudio e Investigación Interdisciplinares para la Formación del Profesorado}

Klaus Rasmussen

University of Copenhagen \& Metropolitan University College

(Recibido: 02 Octubre 2015; Aceptado: 13 Junio 2016; Publicado: 24 Junio 2016)

\section{Resumen}

Esta investigación presenta un estudio de caso sobre las infraestructuras didácticas necesarias para poder implementar los denominados Recorridos de Estudio e Investigación (REI) en la formación del profesorado en un contexto interdisciplinar. Las disciplinas escolares de matemáticas y biología, y lo relativo a su enseñanza, se presentan de forma interconectada a partir del estudio e investigación de una cuestión generatriz sobre la diabetes. Se analiza el conocimiento interdisciplinar que resulta a partir de los diarios escritos por alumnos, usando la Teoría Antropológica de lo Didáctico, y se muestra cómo se consigue combinar dos disciplinas y su didáctica a la vez. Para orientar la gestión de un REI, se propusieron y combinaron dos tipos de dispositivos didácticos: la recolección selectiva de preguntas y las preguntas secundarias. En primer lugar, la recogida selectiva de preguntas aparece como un dispositivo prometedor que, aunque indirectamente, ayuda en la dirección de los REI, sin quitar el grado de autonomía necesario y deseado a los estudiantes. Y, en segundo lugar, las preguntas secundarias, propuestas inicialmente por Yves Chevallard, se ejemplifican en el caso aquí concreto de REI, que nos lleva a proponer una serie de características para su uso.

Palabras clave: Interdisciplinar, proceso de estudio e investigación auto-gestionado, Teoría antropológica de lo didáctico, formación del profesorado, recorridos de estudio e investigación 

Study and Research Path (SRP) is a didactic design format, in which
students and teachers set out to answer a generating question with
more or less autonomy expected from the students (Chevallard, 2006 , 2009; Winsløw, Matheron, \& Mercier, 2013). It has been proposed as a game-changer in the teaching of mathematics (and other disciplines) (Chevallard, 2012), that could move teaching into a new paradigm of "questioning the world": the curriculum is no longer delineated by content described as particular works to be visited, but it is instead expressed as a number of generating questions to be studied. A stronger emphasis on important questions could, according to Chevallard, facilitate a departure from the usual disciplinary compartmentalisation of education. Indeed, a societally important question is not often answerable within a single discipline, so SRPs could be especially attractive in teaching contexts where interdisciplinary inquiries are desired or at least possible. And so, the use of SRPs in interdisciplinary settings have been examined by a number of other researchers: Barquero, Bosch, and Gascón (2013) involved mathematics and population dynamics in an inquiry into the growth of animal populations (see also Barquero, Bosch, \& Gascón, 2008). The SRP implemented by them involved a number of different teaching formats, including lectures, group work and discussions where the students increasingly were given more and more autonomy. New directions of the inquiry process were decided during "academic conferences", after group presentations of work done so far.

Jessen (2014) considered a setting involving mathematics and biology as the partaking disciplines, but where the students worked individually with very limited teacher interaction: The students investigated a set of questions on the dosage and functioning of a painkiller drug and the students' progress was mainly supported by written feedback from the teacher. Others, like Hansen and Winsløw (2011) and Thrane (2009) looked at history and sports respectively in connection with mathematics, both in settings where students prepared written reports to document the process of questions and answers.

These studies all take great interest in the knowledge generated by students, and particularly in the connections developed between the constituent disciplinary domains. Does one discipline support the other? Do they integrate well, or do they give answers to the generating question only in a parallel fashion? What they only scarcely elaborate on, is the means by which the teacher seeks to bring about the Herbartian learning environment, needed for a fruitful inquiry process. The notion of Herbartian attitude was 
introduced by Chevallard (2012) to express a propensity to engage oneself with unanswered questions, to take real or professional interest in pursuing it, to find and examine partial answers, and to generate new derived questions.

The self-sustaining study and research process, which could ideally be the result of such, an attitude does not emerge automatically or easily. As pointed out by Bosch and Winsløw (2015) at least three questions remain open when it comes to the practical realisation of self-sustained research and study processes (here rephrased to reflect disciplinary generality):

I. What are the didactic and disciplinary infrastructures (and resources), as well as the associated knowledge, required for the design, monitoring and evaluation of sustainable study and research processes?

II. What are the institutional conditions needed for teachers to design and implement sustainable study and research processes, and for students to engage in them?

III. What kinds of constraints or even obstacles do institutions and societies commonly offer to such processes?

In the following paragraphs, we examine the first question in the case of a SRP experimented with teacher students in a module shared by mathematics and biology. Question II and III will only be commented on in light of the local institutional conditions.

\section{Design - Context and Theory}

The case SRP was designed, implemented and evaluated by two teacher educators from the disciplines biology and mathematics. The mathematics educator is the author of this paper. When the authorial "we" is employed in the following, it reflects joint considerations of both involved educators. The students participating in the SRP were pre-service teachers in their fourth semester of a special program called Advanced Science Teacher Education (ASTE). This ASTE-program has as its core a number of interdisciplinary courses, one of which is called "Health - risk or chance?" The course covers curricular elements from the biology and mathematics teaching disciplines as prescribed for lower secondary teacher education in Danish university colleges.

A central requirement for the SRP is the necessity for pre-service teachers to have enough means to start the self-sustained study and deal with 


\section{Rasmussen - Study and Research Paths in Teacher Education}

the generating question. The educator has to "know what the pre-service teacher knows", which in the Anthropological Theory of the Didactic means knowledge of the praxeological equipment of the students (see e.g. Chevallard, 1999 for further details on praxeologies). The fundamental objective for the teacher educator is to secure that responsibility to answer the question is assumed, as well as responsibility for the majority of decisions of the study process. The generating question should have the potential of enabling the study community to ask numerous derived questions leading to "contact" with various elements of course curricula. A particular challenge to designing a generating question for SRPs in teacher education is that the pre-service teachers, during the study and research process, should pursue the question on several specific levels: Their own biological and mathematical praxeologies should be strengthened, their grasp of lower secondary pupils' praxeologies should develop, as well as the didactic praxeologies to direct lower secondary pupils' study along the same or similar paths.

Letting teacher students themselves carry out a SRP have, among other elements, been experimented by Barquero, Bosch, and Romo (2015) to deal with the above challenges within teacher education in the monodisciplinary setting of mathematical modelling. Furthermore the SRP must cover questions which are exemplary for the teaching of "the nature of science and mathematics" (Gericke, 2009, pp. 7-8) and more generally for the teaching of similar questions related to biology and mathematics. Finally, in the concrete case, the SRP must fit into the overall descriptions and requirements of "Health - risk or chance?" and the question must be clearly related to descriptions and requirements (curriculum) for the mathematics and biology disciplines in lower secondary school. An important supplementary requirement is that this relevance must be visible to the teacher students.

Here we arrive at an evident contemporary obstacle to SRPs in general: Curricula are presently not formulated in terms of questions. In Danish teacher education, curricula are formulated partly as competences (Blomhøj \& Jensen, 2007) partly as knowledge goals and skill goals where the latter part most closely resembles works to be visited. Educators are naturally concerned whether SRPs will succeed in connecting students to the works. SRPs may be an attractive and intellectually desirable didactic infrastructure, but is it efficient in terms of current goals set by society? Nobody knows. 
Bosch and Winsløw $(2015$, p. 29) point out that, as in the case of actual research processes,

... during the inquiry process, especially when it is not tightly guided, many detours and dead-ends will appear, with the examination of potentially useful answers that will be tested then finally discarded.

Thus, SRPs may run counter to the prevailing didactic contracts, generating a fair amount of scepticism, uncertainty and critique from the students, as well as from members of the noosphere. These expected reservations compelled us to refrain from executing the whole course as SRPs. This, together with the above mentioned need to make sure the students had the means to initially face the generating question, prompted us to limit the extend of the SRP to $20 \%$ of the workload in the Health: Risk or chance? course.

\section{Design Process}

In order to device the crucial generating question, we reviewed the course description and the required curricular elements with the above-mentioned general considerations in mind. The course is described as being composed of three overarching themes, where one, quite ungainly, reads:

Theme 2: Analysis of the distribution of different illness- and health-issues, historically and geographically, including measures of population growth and initiatives to limit such growth. In relation to this, statistical tests will be performed in order to evaluate the risk, e.g. of developing particular diseases, based on genetic analysis.

Obviously a question revolving around some specific health disorder would be ideal, but which? Diabetes, which was finally chosen, possessed a number of promising features: It afflicts both pupils in secondary school and students in pre-service teacher education. Many students know someone who is afflicted with diabetes and thus are likely to be able to identify themselves with the problematic condition. It is a disorder whose causes are not simple or fully known: some have to do with lifestyle, others with genetics. As a lifestyle related disorder, it lends itself readily to statistical investigation, and as an autoimmune disease it relates to human physiology and bodily functioning, corresponding well to several of the knowledge goals and skill 


\section{Rasmussen - Study and Research Paths in Teacher Education}

goals proscribed by the curriculum. The proposal of diabetes was discussed among four educators from the ASTE-education program, and an external scientist doing research on diabetes was consulted. The external scientist could point to current statistical and medical research in the field, assuring us that rich media existed which the students could study. We also reviewed secondary school textbooks and other non-research media (e.g. internet sites) to make sure didactically oriented media were available. A first proposal for the generative question was formulated:

$\mathrm{Q}_{0}$ : How does mathematics and biology in lower secondary

school contribute to children's knowledge concerning diabetes?

This question purposefully mentions both involved disciplines, as well as the institutional target level in the hope of compelling the students to make mathematical, biological and didactical inquiries into the diabetes theme. We note that Danish lower secondary school mathematics includes elements of statistics. This formulation, together with an a priory analysis of possible derived questions, was discussed with other researchers at a course for Ph.D.-students. The suggestions received prompted us to rewrite into the following simpler and less explicitly directed first question:

$\mathrm{Q}_{0}$ : Why is diabetes a challenge for school and society?

The reasoning was that it would be superfluous to mention the disciplines, both because they were implied by the overall course setup, and because it would somewhat diminish the interdisciplinary intention, making it likely that two parallel, but essentially separate, paths would be followed. The latter problem was in fact observed in Hansen and Winsløw (2011). The incorporation of "society" was made to avoid a narrow focus on what pupils in lower secondary school might be able to learn about diabetes, opening up for the students to go as deep into the problematic as their own capacity allowed. A societal focus - often considered in terms of "data" - was believed to have the potential to generate needs for elements of statistics and at the same time avoid an investigation of only pedagogical challenges to teaching. At an intermediary stage $\mathrm{Q}_{0}$ was phrased with the word problem instead of challenge, but was changed due to very specific connotations the students could have for this term, especially within the didactics of mathematics.

The next step in the design process was for the two educators to undertake a final a priori analysis of which sub-questions could likely be derived from $\mathrm{Q}_{0}$. Which sub-questions would draw on answers to other 
questions? Which disciplines would the questions and answers likely draw on? This analysis also served to prepare us for the upcoming lessons, making us aware of knowledge we would have to study in preparation, including questions, which we ourselves found difficult to answer or find suitable media for. The sub-questions and their interrelations can be visualised in the "tree-diagram" form Hansen \& Winsløw (2011), shown in Figure 1.

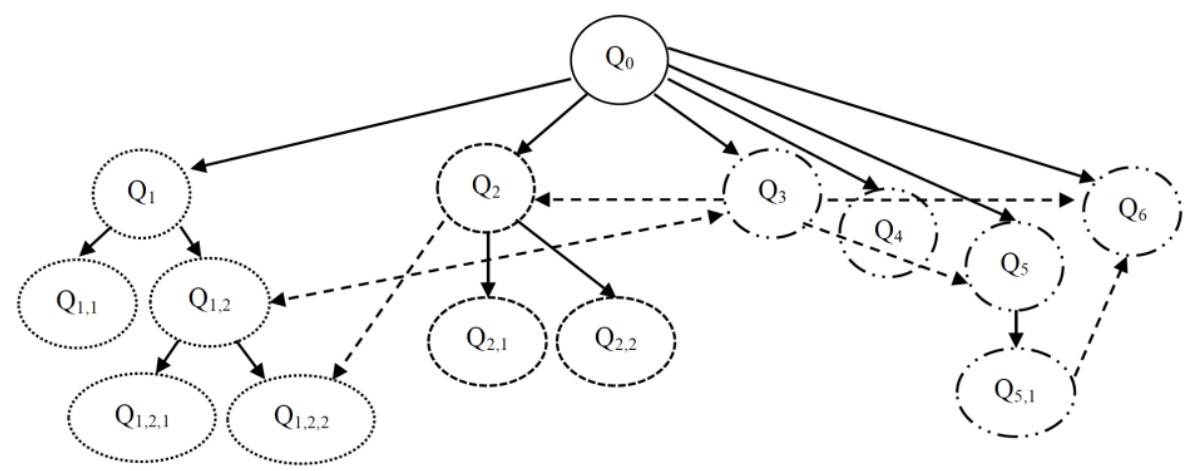

Figure 1. A priori analysis ${ }^{1}$.

The corresponding questions are:

$\mathrm{Q}_{0}$ : Why is diabetes a challenge for school and society?

$\mathrm{Q}_{1}$ : What is diabetes?

$\mathrm{Q}_{1,1}$ : What are the consequences of diabetes?

$\mathrm{Q}_{1,2}$ : What is the cause(s) of diabetes?

$\mathrm{Q}_{1,2,1}$ : How has knowledge of the cause(s) of diabetes changed over time?

$\mathrm{Q}_{1,2,2}$ : How are possible causes identified?

$\mathrm{Q}_{2}$ : How to describe and investigate the distribution of diabetes?

$\mathrm{Q}_{2,1}$ : Who is afflicted with diabetes? (Where do they live (geographic distribution), how old are they, age-distribution, socio-economic distribution etc.)

$\mathrm{Q}_{2,2}$ : How many is afflicted with diabetes? (Distribution in time)

$\mathrm{Q}_{3}$ : What is written about diabetes in school texts? (Curriculum, textbooks, etc.)

$\mathrm{Q}_{4}$ : How are known school lessons on diabetes? (E.g. in published lesson studies)

$\mathrm{Q}_{5}$ : Why choose the theme "diabetes"? Why should it be a concern for schools? 
$\mathrm{Q}_{5,1}$ : What do pupils know about diabetes? What are their experiences? Will diabetes be a motivating theme?

Q6: What could be suitable settings or scenarios wherein to learn about diabetes?

The sub-questions put forward here are clearly generated by us as educators representing two different disciplines, and while we clearly foresaw how $\mathrm{Q}_{0}$ could be attacked from within each of our disciplines, we found it harder to identify connections between the disciplinary branches of the tree structure. Only for $\mathrm{Q}_{2}$, we were able to justify a connection, as it is instrumental to answering $\mathrm{Q}_{1,2,2}$, since statistical methods are invaluable in diabetes research. More connections could be envisaged to, and within, the didactic branch. In particular, answers to $\mathrm{Q}_{3}$ would inevitably shed light on $\mathrm{Q}_{2}$ and $\mathrm{Q}_{1,2}$ through study of media intended for lower secondary school. Conversely $Q_{1,2}$ would enable a critical stance towards the scrutinized media in $\mathrm{Q}_{3}$, while $\mathrm{Q}_{3}$ would further aid the inquiry into $\mathrm{Q}_{5}$ and $\mathrm{Q}_{6}$. Finally $\mathrm{Q}_{5,1}$ nearly begs interaction with pupils (e.g. interviews) which would be greatly beneficial to answering $\mathrm{Q}_{6}$.

The a priori analysis could be continued into even more detailed questions, and is perhaps never ending. The possible connections between branches could be argued to be even more numerous than indicated here, but the analysis serves mainly to prepare us for the upcoming lessons with the students, trying to identify the most likely student questions, answers and difficulties, that could arise within the time available. While the a priori analysis thus support our preparation, helping us identify what kind of knowledge can be developed in a SRP generated by $\mathrm{Q}_{0}$, it also entails a risk: That we use our findings, especially our own answers in normative or prescriptive ways, while directing the students' work. But in a realised SRP, the generating question and the deliberations of the study community (the class) has to be the authority deciding the direction of the SRP. Bosch and Winsløw (2015) highlights this fundamental challenge to manage SRPs and criticize how this is usually circumvented in school contexts:

The decision of when to stop or pursue the study, which is closely related to the inquirers' consideration of what is an acceptable answer and what is not, appears as another important problem in the managing of research and study paths, a problem which is often minimised in the school context by means of the didactic contract: "a solution is acceptable when the teacher considers it to be so". 
There seems to be a potential conflict here: Self-sustained inquiry processes should be allowed to go where the inquirers decide, but inside education pre-set things (works) are to be learnt. Is it possible to reconcile investigative freedom and tight guidance?

We believe it can be done by employing two new pieces of didactic infrastructure. The first is 'selective picking' which put the teacher into a subtle control position in the study community. Selective picking is inspired by a very common structure of teaching in Japan, involving first a session where the pupils work at a problem independently, while the teacher moves around observing and taking note of pupil work especially interesting and relevant for the progression of the lesson (Kikan-Shido phase). Then, the work of these pupils is brought forward in a whole class discussion (Neriage phase) (see e.g. Shimizu, 1999). This practice was also pursued in the case, as we shall see in the next paragraph.

The other didactic infrastructure is 'control questions' or 'side questions', an idea coined by Yves Chevallard:

Any question $\mathrm{Q}$ can indeed be supplemented meaningfully by one or a series of "side questions" $\mathrm{Q}^{*}$ that will be touchstones for controlling the quality, thoroughness and profundity of an inquiry into question Q. It is in this way that it becomes possible to point out meaningfully - and not out of sheer pretentiousness - the utility of such and such work $O$ to get deeper into the question studied (Chevallard, 2012)

The exact nature of such control or side questions is, to our knowledge, not systematically explored. We would like to remark that we prefer the term 'side question' as "control questions" carries strong connotations to overt teacher control, which we believe runs contrary to the aim of self-sustained study and research processes. On the basis of our case, the final section contains some suggestions as to the quality and function of side questions, in order for them to act as a steering device, without taking away the desired autonomy of SRPs.

\section{Guiding and Monitoring the SRP}

The case SRP was planned for a student workload of approximately 40 hours, with 16 hours being set aside for whole class teaching, and the rest to student's individual work. The SRP was experimented with 14 students over 
the course of 4 weeks in the spring semester of 2015. A script was prepared for the succession of lessons and individual work periods. The overall setup was divided into four stages: First a preparatory stage: A one lesson introduction to the work structure and a first generation of sub-questions from the initial question. Then three main stages: five lessons in one day, spaced one week apart, with the individual work to be done in between. Between the preparatory stage and the first main stage the students carried out individual media search. The first main stage began with a conference based on a tree-diagram rendition of the student-generated sub-questions (see also Figure 3 below). Just as in Barquero et al. (2008), conferences were used as a means for the class (the study community) to clarify which avenues of inquiry they would first pursue. Each individual student was at this point given complete autonomy in his or her choices; either educator disclosed no indication of preferred direction. Five small groups were formed, based on agreements to investigate common questions in the subsequent more research-oriented part of the lessons. In the final hour of the day, another conference were held where each group shortly presented the results of their investigations and stated what study of media they would undertake until the next main stage. The day ended with a session where each student individually wrote a note specifying an issue relating to the inquiry of the day, which he or she would like the educators to elaborate on in the course of main stage two. These notes were collected by the educators and carefully reviewed immediately after class. This is the crux of the 'selective picking': from the fourteen written issues, we picked one each, that we deemed most promising, in the sense that a presentation based on the particular issue would connect well with the curricula for the whole module. By this choice, we could indicate a direction and make it easier for the students to carry on their investigations in that direction with greater depth and profundity.

Main stage two consisted of a session dedicated to formulate questions to an invited 'resource person', in this case a person who had lived with diabetes all through her school years. This presentation and discussion session was followed by the two educators' presentations, and subsequently the first conference of the day. The conference debated the way forward in light of the three presentations. A sort of consensus among the groups of students was reached as to what research would be undertaken in next couple 
of hours. At the end of this stage came the final conference of the day, and the second and final round of writing down issues for "selective picking".

Main stage three commenced with the educator presentations followed by a short conference to determine the direction of inquiry for each small group of students. At the end of the day a final session was held with the purpose of drawing a "tree" of questions and answers reflecting the knowledge obtained by the study community as a whole. This served to bring a sense of closure even though the path could carry on, and also highlighting the individual study and research paths' relation to answering the initial question Q.

In order to monitor, and to document for research purposes, the progress along the path, each student was asked to keep a sort of electronic diary. This is quite simply a document in which the student writes down what media had been consulted, what notes were taken, what conclusions had been drawn, what calculations had been made etc. -in short, all the messy scribbling that anyway arise in the course of an inquiry process. No special format was required, except that it had to be consecutively recorded and nothing erased.

\section{Realised SRPs}

As mentioned above, the very first conference was focused on students' derived questions, formulated in view of answering $\mathrm{Q}_{0}$. The questions were compiled into a tree-structure and discussed with the students (Figure 2).

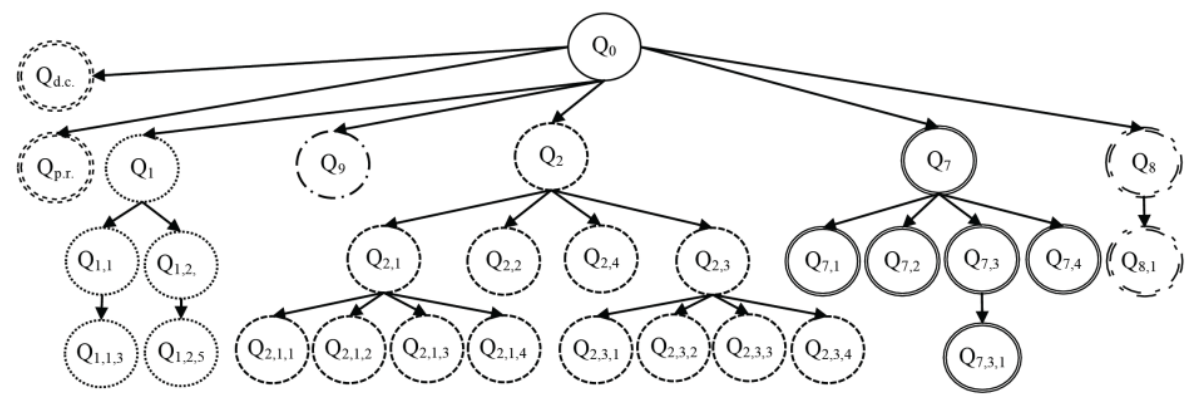

Figure 2. A posteriori analysis of derived sub-questions for the study community as a whole. 
As we can see, it is a much larger arborescence than our own a priori analysis.

$\mathrm{Q}_{0}$ : Why is diabetes a challenge for school and society?

$\mathrm{Q}_{1}$ : What is diabetes?

$\mathrm{Q}_{1,1}$ : What are the consequences of diabetes? (What does it entail for the individual to be afflicted by diabetes?)

$\mathrm{Q}_{1,1,3}$ : Which sequelae does diabetes entail?

$\mathrm{Q}_{1,2}$ : What is the cause(s) of diabetes? (What factors influence the development of diabetes?)

$\mathrm{Q}_{1,2,5}$ : What is the difference between type 1 and type 2 diabetes?

$\mathrm{Q}_{2}$ : How to describe and investigate the distribution of diabetes? (What does statistics say about diabetes regarding age, diet, genetics and mortality?

$\mathrm{Q}_{2,1}$ : Who is afflicted with diabetes? (Where do they live (geographic distribution), how old are they, age-distribution, socioeconomic distribution etc.)

$\mathrm{Q}_{2,1,1}$ : What age group is typically afflicted by the illness?

$\mathrm{Q}_{2,1,2}$ : How many school-teachers are diabetics?

$\mathrm{Q}_{2,1,3}$ : Does diabetics have more sick leave?

$\mathrm{Q}_{2,1,4}$ : Does diabetics suffer greater unemployment

$\mathrm{Q}_{2,2}$ : How many are afflicted with diabetes? (Distribution in time)

$\mathrm{Q}_{2,3}$ : How to describe diabetes as an economic challenge?

$\mathrm{Q}_{2,3,1}$ : What does the average diabetic cost society?

$\mathrm{Q}_{2,3,2}$ : How many money does the country spend on diabetes research subsidy?

$\mathrm{Q}_{2,3,3}$ : How many money does the country spend on diabetes medicine subsidy?

$\mathrm{Q}_{2,3,4}$ : Is more focus on prevention economically preferable, or is treatment of developed cases cheaper?

$\mathrm{Q}_{2,4}$ : What is the distribution between type 1 and type 2 diabetes?

$\mathrm{Q}_{2,4,1}$ : Which type is the most expensive for society?

$\mathrm{Q}_{7}$ : What role does school play in pupils' diabetes?

$\mathrm{Q}_{7,1}$ : What fosters diabetes - and do we have to inform about it in school?

$\mathrm{Q}_{7,2}$ : Does pupils with diabetes have special social challenges?

$\mathrm{Q}_{7,3}$ : Is special considerations to be taken if a pupil has diabetes?

$\mathrm{Q}_{7,3,1}$ : What about pupils with fear of needles?

$\mathrm{Q}_{7,4}$ : How substantial knowledge must a teacher have of diabetes, if a pupils is afflicted with diabetes? 
Q8: What consequences does it have for teaching that some pupils have diabetes?

$\mathrm{Q}_{8,1}$ : Is diabetes a contributory cause of pupils having difficulty concentrating?

$\mathrm{Q}_{9}$ : Is there a relationship between diabetes and obesity?

$\mathrm{Q}_{\text {d.c.: }}$ : How is diabetes connected to health? Who decides if diabetes is a challenge at all? Why ask about the reasons for the challenge instead of how to solve it?

$\mathrm{Q}_{\text {p.r. }}$ : What can the individual person do to avoid diabetes?

We notice that questions of didactic nature $\left(\mathrm{Q}_{3}-\mathrm{Q}_{6}\right)$ are not present; instead a number of questions related to general social and pedagogical challenges of being a teacher are raised $\left(\mathrm{Q}_{7}\right)$. Although $\mathrm{Q}_{8}$ concerns teaching, is does not seem to be specific to diabetes as a topic for teaching. The disciplinary oriented question strings $\left(\mathrm{Q}_{1}\right.$ and $\left.\mathrm{Q}_{2}\right)$ are clearly present, with the mathematical one being the most strongly elaborated. $Q_{9}$ springs directly from $\mathrm{Q}_{0}$ and while it is very specific, it lends itself equally well to be answered from the perspective of each discipline. Then there are two residual groups of questions: $\mathrm{Q}_{\text {d.c. }}$ question the didactic setup of the $\mathrm{SRP}$, and could be seen as a metadidactic resistance to the change in didactical contract (signified by the subscript 'd.c.') (Brousseau, 1997). Qp.r. represents questions, which deal with health information and a personal responsibility (signified by subscript 'p.r.') of citizens to avoid becoming a victim of diabetes. These are mostly connected to social dynamics and moral education, and are as such valid for the answering of $\mathrm{Q}_{0}$, but only marginally justifiable endeavours within the frame of the case course.

Ten of the fourteen students managed to participate in all phases of the SRP. And their diaries have all been analysed carefully. The realised paths can be divided in three groups, and in the following I present one path from each. The first group (four paths, student D, H, PP, and MB) is characterised by not showing any investigation of didactic questions. Instead they exhibit a disciplinary inquiry into both statistical and medical questions related to diabetes (see e.g. Figure 3).

$\mathrm{Q}_{0}$ : Why is diabetes a challenge for school and society?

$\mathrm{Q}_{1,1}$ : What are the consequences of diabetes? (What does it entail

for the individual to be afflicted by diabetes?)

$\mathrm{Q}_{1,1,1}$ : How often do you need to see a doctor? 
$\mathrm{Q}_{1,1,2}$ : What about money for medicine?

$\mathrm{Q}_{1,1,3}$ : Which sequelae does diabetes entail?

$\mathrm{Q}_{1,2}$ : What is the cause(s) of diabetes? (Is Danish lifestyle directly related to diabetes?)

$\mathrm{Q}_{1,2,3}$ : Is lack of physical activity a cause for the increase in diabetics?)

$\mathrm{Q}_{1,2,4}$ : Is unhealthy diet a cause for the increase in diabetics?

$\mathrm{Q}_{2,1}$ : Who is afflicted with diabetes? (How old are they, agedistribution)

$\mathrm{Q}_{2,2}$ : How many are afflicted with diabetes? (Is the increase in diabetics just a consequence of better diagnostics?)

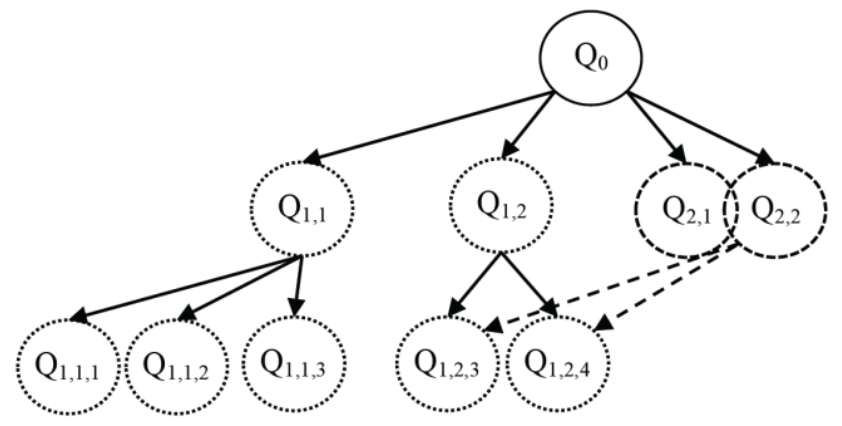

Figure 3. A posteriori analysis of realized SRP for student D.

There is generally a slightly greater emphasis on the biological questions, but often backed up by mathematical knowledge and connections among the disciplines are discernible. In the case of Student D (Figure 3), where the disciplinary interaction is the most explicit, questions $\mathrm{Q}_{2,1}$ and $\mathrm{Q}_{2,2}$ are answered statistically in an intertwined fashion and the answers are used to draw conclusions about possible biological cause and effect. (Dashed arrow to $\mathrm{Q}_{1,2,3}$ and $\left.\mathrm{Q}_{1,2,4}\right) \mathrm{Q}_{1,2,4}$ has relation to $\mathrm{Q}_{9}$ but is more general. It could be argued that $\mathrm{Q}_{9}$ is here indirectly answered using mathematical knowledge.

The second group (three paths, student $\mathrm{C}, \mathrm{K}$ and PGK) considers mainly biological questions, making next to no reference to mathematical knowledge, and deal mainly with possible consequences for the work as a teacher by having diabetics in the classroom. 


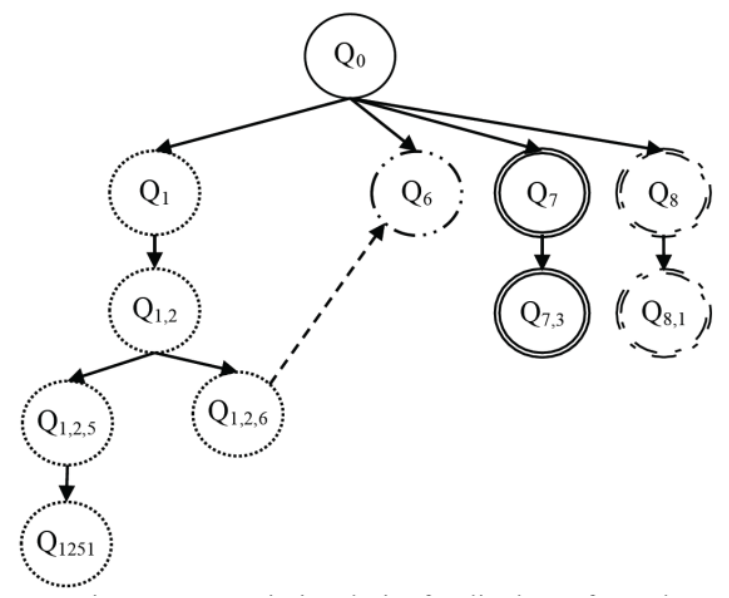

Figure 4. A posteriori analysis of realized SRP for student C.

$\mathrm{Q}_{0}$ : Why is diabetes a challenge for school and society?

$\mathrm{Q}_{1}$ : What is diabetes?

$\mathrm{Q}_{1,2}$ : What is the cause(s) of diabetes? (What factors influence the development of diabetes?)

$\mathrm{Q}_{1,2,5}$ : What is the difference between type 1 and type 2 ?

$\mathrm{Q}_{1251}$ : What other types of diabetes exist?

$\mathrm{Q}_{1,2,6}$ : How does insulin function in the healthy body?

Q6: What could be suitable settings or scenarios wherein to learn about diabetes?

$\mathrm{Q}_{7}$ : What role does school play in pupils' diabetes?

$\mathrm{Q}_{7,3}$ : Is special considerations to be taken if a pupil has diabetes?

$\mathrm{Q}_{8}$ : What consequences does it have for teaching that some pupils have diabetes?

$\mathrm{Q}_{8,1}$ : Is diabetes a contributory cause of pupils having difficulty concentrating?

In the specific case of Student C (Figure 4), mathematics is mentioned only as notes to the educator presentations, and there is a suggestion to inform pupils about diabetes on the basis of statistical information regarding which population groups have the greater risk. However when the aim is inquiry rather than 'just' informing, the knowledge base is taken from biology. For instance, it is suggested that learning about 'insulin mode of action' could be the way didactic trajectory towards learning about diabetes. Thus there is a tenuous connection from $\mathrm{Q}_{1,2,6}$ to $\mathrm{Q}_{6}$. 
The third group (three paths, student M, L and MLN) is characterised by not considering didactic questions at all, and staying nearly exclusively within one of the disciplines.

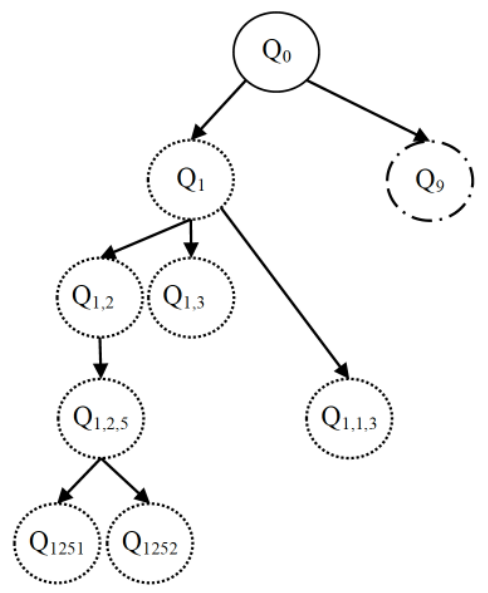

Figure 5. A posteriori analysis of realized SRP for student M

$\mathrm{Q}_{0}$ : Why is diabetes a challenge for school and society?

$\mathrm{Q}_{1}$ : What is diabetes?

$\mathrm{Q}_{1,1,3}$ : Which sequelae does diabetes entail?

$\mathrm{Q}_{1,2}$ : What is the cause(s) of diabetes? (What factors influence the development of diabetes?)

$\mathrm{Q}_{1,2,5}$ : What is the difference between type 1 and type 2?

$\mathrm{Q}_{1251}$ : What other types of diabetes exist?

$\mathrm{Q}_{1252}$ : Is diabetes hereditary? How do genes predispose for diabetes?

$\mathrm{Q}_{9}$ : Is there a relationship between diabetes and obesity?

Student M (Figure 5) is a representative of the third group and is the only one to consider hereditary aspects of diabetes $\left(\mathrm{Q}_{1252}\right)$. In fact, Student $\mathrm{M}$ uses the genetic aspect of diabetes in answering most questions in the biology branch. However, $\mathrm{Q}_{9}$ is not dealt with using genetics as a common mode of explanation of relationships between diabetes and obesity, but it is nevertheless pursued within the frame of school biology. Notice the contrast to Student D where mathematics was employed. 


\section{Selectively Picked Issues and Their Influence on Student SRP}

In this section we take a closer look on the issues proposed by the students, those picked by us as educators, our presentations based on them, and their traces as they appear in the student logs. The first round of formulating issues was marred by confusion, as the students were obviously not used to being given this responsibility. Only three issues came to our attention: How is insulin produced in the healthy body? What happens "biologically"? Do diabetics die earlier than others? Thus there was not much selective picking possible. We opted to do two presentations dealing with all three proposed issues to emphasize the student ownership and responsibility for the study process. We also made a point of mentioning which students had proposed the questions. One (standard transmissive) presentation handled the first two issues from the perspective of the biology discipline, focussing on the physiological processes of insulin production and Type 1 diabetes. The other exemplified a statistical inquiry of the third issue presented as a written succession of questions and answers, while explicitly demonstrating the dialectic between the study of media, and construction and research in a milieu.

The second round, significantly more successful, produced twelve issues from which we choose: "Diet and exercise in relation to improve life with type 2 diabetes" and "Help me understand the statistics in the research paper: A common Greenlandic TBC1D4 variant confers muscle insulin resistance and type 2 diabetes" (Moltke et al., 2014). The former was dealt with in a presentation taking statistical findings as the point of departure, then moving into biological explanations for the observed statistical correlations between diet and exercise. This was done in a fashion, which again emphasised the succession of questions and answers. The presentation based on the second issue concerning the research paper was standard transmissive, giving explanations of how to calculate and interpret p-values as presented in the paper. In should be noted here that the paper which the question refers to was found independently and used by Student $\mathrm{M}$ as she studied $\mathrm{Q}_{1252}$.

The teacher presentations of the two selected issues are indeed referenced in the student notes/logs. However it is not abundantly evident that the students took the material to heart, in the sense that it had a clear influence on their paths. For instance, it was our hope that student $M$ would have deviated from the "pure biology" path as a consequence of being exposed to 
an explanation of the statistics in the research paper. We also hoped that by focussing on these aspects, other students would have been encouraged to delve deeper into the genetic and statistical research surrounding diabetes. In general there were fewer results of this in terms of statistical inquiry, than in terms of biological ones. For instance, Student $\mathrm{C}$ concluded in her log from the first round of issues that diabetics statistically die ten year earlier than non-diabetics, but this did not prompt her to do further statistical investigations, instead she sought out biological explanations for this statistical fact, as she expanded her answer of $\mathrm{Q}_{1,1,3}$. From the viewpoint of school mathematics this is perhaps less satisfactory, but in the interdisciplinary setting we believe it shows a quite common challenge to overcome the perception that statistical analysis is somehow mere technical afterthoughts, while in fact the statistical interpretation may be crucial to produce meaningful and precise interpretations of data.

We acknowledge that we cannot definitively conclude from this short SRP trial whether "selective picking of student raised issues" will be an important piece of didactic infrastructure to guide the study process. Nevertheless it did serve an institutional need for a space accommodating "visits" of mandatory curricular works that were timely in the sense of following the direction of the SRP, and thus making the works less decoupled from questions they provide answers to. We would also like to emphasize that "selective picking" is not a didactic infrastructure, which can radically and automatically change the direction of the study process.

We would have liked the students to venture more into diabetes as a topic for teaching, but none of the student proposed issues pointed in that direction, making us unable to emphasise this line of inquiry. There has to be at least one student who identified the need. At the very end of her log, Student H, who had made a thoroughly bi-disciplinary inquiry, lamented her missing path into the didactic branch: "... with all I have investigated myself and what the others have shared, I am left with a lack of knowledge about how I am going to teach diabetes in school". The fact that others had looked into didactic questions came to her attention only during the very last conference. Another round of posing issues to be selected for educator presentation could have drawn attention to this, at a time when the students were disciplinarily prepared for the study of didactic questions. We thus hypothesize that conferences and the selective picking, in conjunction with a 
larger time frame than we had, could constitute a viable didactic infrastructure of SRPs in this setting.

\section{Discussion}

The qualities of students' answers are not evident from the tree diagrams, and the depth or superficiality of their inquiry is not assessed in this paper. We have looked for didactic infrastructure to guide self-sustained study and research with an interdisciplinary nature. I have only analysed what can be seen from the logs, even though obviously more happened than what is written there. After the SRP, the students were asked to participate in an evaluation of their experience. An interesting point was that all of them indicated that they found the duration too long and demanding, in terms of having to keep themselves going in the exploration of questions.

Having or acquiring a Herbartian attitude is obviously strenuous. The change of didactic contract is mentally exhausting, and may only succeed through continued exposure. It is a fact from the analysis of the individual paths that the students only managed to deal with a maximum of two branches of the envisioned path, which suggests that the duration of the SRP should have been somewhat longer, contrary to the opinion of the students themselves.

Making these ends meet may require a more deliberate use of side questions as introduced above. We propose that such questions should be very concrete and deeply specific, such as: How to calculate and interpret the test-statistic for odds ratio-test? What is the biological mechanism for glucose transport in fat cells? What does school textbook X say about obesity? - introducing "study and research activities" which, as much as possible, deepen the questions identified by students. Evidently, this last desideratum implies a difficulty: How to avoid that students are given such questions without going through a path that motivates them? Clearly, one should avoid that side questions simply make students and educators return to visiting monuments, concealed as monumental questions with no reason for the asking. To avoid this predicament we consider that side questions, as exemplified above, could be used for two separate purposes: going deeper in the path, or going wider. In order to go deep, we consider that timing is essential. Side questions should not be stated early on in the SRP, rather they should be posed to students when they are well under way, but need a little 
push going to the depth which the curriculum, or the educator, expects them to. Using side questions to go wider needs to be expanding from the topics which has already to some extent been conquered by the study community (or possibly a part of it); using side questions to try to make the students jump to another branch of the SRP would seem futile.

\section{Concluding Remarks}

In this paper I have presented our design and evaluation of a study and research path as a priori and a posteriori analysis respectively. It was seen in the a posteriori analysis that students paths fell into three categories, where all pursued at most two branches of the envisaged path: Biology and mathematics interaction, Biology and didactics interaction, and finally biology or mathematics separately. In order to monitor the students' progression along the path, we have employed the use of written diaries, which were handed in after each of the three main phases. Likewise, conferences have been part of the didactic infrastructure to decide on the study community's direction along the path. Most importantly, students have been asked to pose issues critical to their investigation as suggestion for presentation by the educators. Among these issues we have selectively picked the ones we judged would lead the path in desirable directions. We have seen that uptake from these presentations were traceable in the diaries, more so for presentations related to biology than to statistics, and also towards structuring the diary as a conscious progression between questions and answers. The guiding function of "selective picking" was thus only partially successful, but promising for the subtle control of the direction in study and research processes while maintaining significant student autonomy. As a more fast-acting didactic infrastructure, we have discussed the possible quality and appropriateness of side questions proposed by Yves Chevallard, and found them suitable to attain greater depth of study, while we remain wary of their fitness to guide students towards other directions in their study and research path.

\section{Acknowledgements}

I would like to extend my profound gratitude to Henrik Levinsen for many interesting discussions during the planning and implementation of "Health - risk or chance?" Kjeld 
Poulsen provided valuable insight into the statistical research around diabetes and Carl Winsløw were as always a great source of inspiration and valuable comments.

\section{Notes}

${ }^{1}$ Tree diagram showing the generating question and the first sub questions. Short and long dashed circles respectively indicate questions judged as belonging to biology and mathematics respectively; whereas combination dashed circles indicate questions of a more didactical nature. Dashed arrows indicate that the receiving question is expected to draw on knowledge from the answers to originating questions.

\section{References}

Barquero, B., Bosch, M., \& Gascón, J. (2008). Using research and study courses for teaching mathematical modelling at university level (pp. 2050-2059). In D. Pitta-Pantazi \& G. Pilippou (Eds.), Proceedings of the 5th Conference of the European Society for Research in Mathematics Education, Larnaca, Cyprus.

Barquero, B., Bosch, M., \& Gascón, J. (2013). The Ecological Dimension in the Teaching of Mathematical Modelling at University.

Recherches en Didactique des Mathématiques, 33(3), 307-338.

Barquero, B., Bosch, M., \& Romo, A. (2015). A Study and Research Path on Mathematical Modelling for Teacher Education. Paper presented at the CERME 9, Prague.

Blomhøj, M., \& Jensen, T. (2007). What's all the Fuss about Competencies? In W. Blum, P. Galbraith, H.-W. Henn \& M. Niss (Eds.), Modelling and Applications in Mathematics Education (Vol. 10, pp. 45-56). New York: Springer.

Bosch, M., \& Winsløw, C. (2015). Linking Problem Solving and Learning Contents: The Challenge of Self-Sustained Study and Research Processes. Recherches en Didactique des Mathématiques, 35(2), 357399.

Brousseau, G. (1997). The Didactical Contract: The Teacher, The Student and the Milieu. In N. Balacheff, M. Cooper, R. Sutherland \& V. Warfield (Eds.), Theory of didactical situations in mathematics (pp. 226-249). Dordrecht: Kluwer Academic Publishers. 
Chevallard, Y. (1999). L'analyse de pratiques enseignantes en théories anthropologiques du didactique. Recherches en Didactique des Mathématiques, 19(2), 221-266.

Chevallard, Y. (2006). Steps towards a new epistemology in mathematics education. In M. Bosch (Ed.), Proceedings of the 4th Conference of the European Society for Research in Mathematics Education. (pp. 21-30). Barcelona: FUNDEMI IQS.

Chevallard, Y. (2009). Remarques sur la notion d'infrastructure didactique et sur le rôle des PER. Journées Ampère. Lyon.

Chevallard, Y. (2015). Teaching Mathematics in Tomorrow's Society: A Case for an Oncomming Counterparadigm. In S. J. Cho (Ed.), Proceedings of the 12th International Congress on Mathematical Education (pp. 173-187). Seoul, Korea: Springer.

Gericke, N. (2009). Science versus School-science; Multiple Models in Genetics - The depiction of Gene Function in Upper Secondary Textbooks and its Influence on Students' Understanding. Doctoral Dissertation. Karlstads Universitet, Karlstad.

Hansen, B., \& Winsløw, C. (2011). Research and study course diagrams as an analytic tool: The case of bi-disciplinary projects combining mathematics and history. Paper presented at the 3rd Conference of the Anthropological Theory of Didactics, Barcelona.

Jessen, B. E. (2014). How can research and study courses contribute to the teaching of mathematics in an interdisciplinary setting? Annales de Didactique et des Sciences Cognitives.

Moltke, I., Grarup, N., Jorgensen, M. E., Bjerregaard, P., Treebak, J. T., Fumagalli, M., . . . Hansen, T. (2014). A common Greenlandic TBC1D4 variant confers muscle insulin resistance and type 2 diabetes. [Letter]. Nature, 512(7513), 190-193. doi: 10.1038/nature 13425

Shimizu, Y. (1999). Aspects of mathematics teacher education in Japan: Focusing on teachers' roles. Journal of Mathematics Teacher Education, 2(1), 107-116. doi: 10.1023/A:1009960710624

Thrane, T. (2009). Design og test af RSC-forløb om vektorfunktioner og bevægelse. Retrieved from

http://www.ind.ku.dk/publikationer/studenterserien/studenterserie12/

Winsløw, C., Matheron, Y., \& Mercier, A. (2013). Study and Research Courses as an Epistemological Model for Didactics. Educational 
Studies of Mathematics, 83(2), 267-284. doi: 10.1007/s10649-0129453-3

Klaus Rasmussen is associated professor at the Metropolitan University College, Department of School and Learning, and attached researcher to the University of Copenhagen, Denmark.

Contact Address: Direct correspondence concerning this article, should be addressed to the author. Postal address: Nyelandsvej 27, 2000 Frederiksberg, Copenhagen, Denmark. Email: klra@phmetropol.dk 